\title{
Multimedia Technology Application in Foreign Language Multimodal Teaching
}

Xia Wang ${ }^{1}$

${ }^{1}$ Foreign Language Teaching and Research Department, JiLin University of Finance and Economics, China

Keywords: Multimedia technology, Foreign language teaching, Multimodal, Foreign language teaching.

\begin{abstract}
The diversity of information communication requirements of the traditional English teaching mode is multimodal teaching mode. Based on the connotation and multimodal interactive teaching theory as a foundation, discusses the multimedia English teaching in the teaching of multimodal interaction between subject and object. The multimodal interaction model make the classroom teaching, presents a kind of vertical to help solve high investment problems such as low efficiency in English teaching.
\end{abstract}

\section{Introduction}

The word "mode" has a long history, beginning in the $1990 \mathrm{~s}$ language educational world be more and more attention. With the development of the society and the progress of science and technology, especially with the wide use of digital, network and multimedia technology, the traditional grammar that is pair of language images, colors, sounds, and movements, such as symbol in modern communication is no longer in a secondary position, but is and the symbol of the language symbol together to form a wider resources to participate constructing meaning. Therefore, modern people's communication is no longer a single mode of communication; communication mode has become the mainstream [1]. According to the views of social semiotics, meaning so powerful and widely consist in the visual, auditory, behavior, expression and action, and other social resources system of symbols, only pay attention to the language is not enough, because there is no a single symbol can be isolated completely understand. In a strict sense, all communication is in reality many modal.

At present, the school's English teaching mode is given priority to with single modal, the classroom teachers' use a lot of time to language, students passively listen to; Teaching means on the blackboard with chalk, supplemented by the traditional way of recorder. Practice has proved that this kind of traditional teaching mode focusing on the language knowledge, professor, and a single classroom teaching way, didn't make full use of multimedia teaching means, English learning software, network teaching, teaching efficiency is low [1]. Even if the student takes an exam the ability will be improved, but the actual need to communicate in spoken English, most of the students of English is still the "dumb English".

Along with the wide application of network technology and multimedia technology, the teacher in class play space is more and more big, can take advantage of the multimedia courseware, images, voice, video as auxiliary teaching means, teaching mode to multimodal teaching. The use of multimodal can stimulate the students' vision, hearing, sense organs to mobilize their enthusiasm of autonomous learning, arouse their interest in learning, deepen the students' mastery of knowledge at the same time also can improve their language ability of practical application.

\section{The application of multimedia technology in English teaching}

Multimedia technology is what? Multimedia technology refers to the text, graphics, sound, animation, video and other media information through computer processing form together to present knowledge of information technology. It has the strong integration, interactive features. It to provide a variety of teaching and learning can select function, to make the students in the classroom of a large number of high-quality comprehensive training of listening, speaking, reading and writing [2]. 
Using electronic recording media, train students' correct pronunciation and intonation. Students for a long time under the environment of a standard pronunciation, and hears about standard pronunciation of native speakers of English countries, combined with high density, a large number of students oral English training, students can independently the correct pronunciation, laying a good voice.

Using audio and video effect, highlight the heuristic teaching of classroom teaching. To introduce new lesson aims to the students' attention to the study of the knowledge, and to establish contact with previous knowledge structure of the material, in the conventional teaching is not easy to do this. If with the help of multimedia, to provide a bright, clear image, can make students quickly focus on the study object, through careful observation slides projection, inspire thinking, arouse the links with the previous knowledge, and improve the comprehension in comparison with contact.

Using the multimedia establishment situation, make the class content and vivid image, break through the teaching difficulties. In the traditional teaching process, restricted by time and space, in the interpretation of the new lesson, to make students to break through a certain teaching difficulty, very difficult, take a heap of teaching wall charts; also want to write several big blackboards, sweat clip back. The multimedia solved this difficult problem. Multimedia can make use of the function of the animation, graphics and image transformation, dynamic static graphics in the teaching material, to reveal the rich connotation of graphics, image, help students to in-depth understanding of the essence, intuitive, image, multimedia can help students with a variety of sensory features colorful and learning. Abstract thinking, logical thinking and language expression and so on under the action of the obstacles in the computer be reconciled, disappeared, which reduces the difficulty of learning, to break through the teaching difficulties, teaching key solved smoothly. In view of the teaching difficult point using the multimedia technology with intuitive, image of painting materials, students of the impression is profound. Graphics is not language, but the more intuitive than words and images, inclusive information more than words. In teaching the new teaching stage, can let the students listen to repeatedly, repeatedly to imitate and achieve proficiency, students on the basis of a lot of listening to and be understood by imitation and internalize language programs into their own knowledge structure. In the teaching of practice stage, make some pictures, for effective oral communication training for students, at the same time with problem sets of special training, so that students in a limited amount of class more comprehensive training in listening, speaking, reading and writing, at the same time, to achieve a basic knowledge of English language has also been basic skills training, to think in English and the ability to express directly receive training. At the end of the teaching period, the use of multimedia courseware for summary. Summary is short, but this lesson content review and knowledge to summarize, can make the students grasp the knowledge structure, consolidate the knowledge. And sound, vivid image, to facilitate students understanding, digestion and absorption.

\section{The role of multimedia technology in English teaching}

Modern education should pay special attention to the all-round development of human beings, attaches great importance to the person's comprehensive quality. Time needs to have practical ability, communication ability and innovation ability of comprehensive talent; each teacher is faced with new challenges [2]. How to make full use of multimedia in English teaching of information technology, consciously undertake to the student various ability, is our each English teacher should reflect and explore. Below I talk about the use of multimedia in English teaching to some experience of cultivating the ability of students.

Stimulate students' interest in learning, improve the students' enthusiasm to participate in classroom learning. The first element of interest and the hobby is learning, learning interest is the root of the learning motivation is an intrinsic psychological factors to overcome the difficulty, students learned knowledge to him once you have the interest, will be tireless, learn more and more love to learn. Use of multimedia technology, through the actual contact life, choose close to the life, has a modern example, illustrated, fully mobilize students' senses, arouse their learning enthusiasm, is advantageous to the teaching activities and in-depth, to expand the minds of students, make students actively participate in the learning content [3]. Such as English nouns have a lot of fruits and vegetables, like watermelon, apple, grape, peach, $\mathrm{m}$ - angora, onion, pepper, cabbage,, potato, lettuce, 
and so on, have some food and had not seen each other words students, learning boring and hard to remember. To find the relevant pictures, use Photoshop tool processing, in the form of animation set in the picture with the word pronunciation. Click on the picture with the words of the movie, let the student sea food pictures read remember the words. Interesting images, image is clear physical attracted the attention of students; deepen their impression of the word.

To cultivate students' innovative ability. In the process of the traditional teaching, due to time and space limitation, after the curriculum reform some teaching material content can't image to show students deeply. And with the aid of multimedia teaching, starting from the students' cognitive regularity and physiology characteristic, provides students with an adjustable itself, listening, reading, writing, learning environment, give full play to their senses, and arouse their learning enthusiasm, so that their imagination and creativity to play within a relatively large space [3]. As long as meet the requirements of the spirit of students, and students' learning process is full of innovative spirit and creativity.

Timely feedback, inspire and promote the students to "discover" rule and knowledge, improve my English self-study ability. The involvement of the multimedia CAI for teaching and learning provides a wide variety of choice function, at the same time provide study results at any time, timely feedback of learning information and can choose the learning path, provides students with an adjustable itself, listening, reading, writing, creative integration of learning environment [4]. Now there are many software, students can choose courses according to their own pace and interest, as long as a finished, students immediately know, to get the praise, the wrong will be friendly to inform where is wrong, so that the students always test their own knowledge structure what went wrong, in a timely manner to correct their mistakes, cultivate students themselves to find the patterns and knowledge and the ability to self-study.

\section{The multimodal interactive multimedia teaching mode}

Multimodal interaction is the learner in the multimedia teaching, multimedia courseware, teachers through the computer network and the realization of network teaching platform of multimodal interaction. Learners (body) by multimedia courseware and network teaching platform provided by the "situation", "collaboration", "session" conditions, complete knowledge construction, implementing individualized learning;Teacher (leading) mainly through the network teaching platform to play a leading role, designing and building learning environment [4]. Multimodal interactive learning under the multimedia environment refers to the computer technology and network resources created under the network environment, teachers' teaching design theory and method, in particular to organize and guide way, application of teaching strategy, platform for students to use language, put stress on their language learning ability, forcing them to select in the situational context of changes in language form, promoting languages and situational context, the fit between the students and teachers and other students, the computer, the resources of multidirectional interaction, so as to arouse the enthusiasm of students learning and initiative, to train the innovative consciousness of foreign language learners, makes the language learning to be a more natural and reasonable behavior, make the students form active discovery, active thinking, and actively explore the quality of learning. The following discussed the multimodal interaction between them.

Multimedia teaching in the teaching the multimodal interaction between the main body. "Multimodal teaching" concept was created in the background of highly developed modern information technology. Humans have into the hypertext age from oral and reading and writing, can be a wide range of information through the Internet interactive activities, for example, E-mail, MSN, BBS, QQ chat, video communication, role playing games and so on media, has had a distinctive meaning construction of register [5]. Using these resources, in the teaching, teachers can choose colorful textual material, and editing processes, and present themselves to the students in the form of multimodal teaching intention. So, can use more English teaching mode, such as audio, visual and tactile experience and multi-sensory stimulation, provide students with sound, like, figure, surrounded by interactive training context, causes the student to obtain the communicative awareness and pragmatic competence [5]. And multimodal teaching make the institution of constructivism 
learning environment more convenient, because the multimodal images, text, voice, multimedia equipment, the organic combination of teachers and students, each mode is a symbolic resources, work on the construction of meaning;And, multimedia and network technologies such as information carrier has diversity, integration, interactivity, distribution and advantage of digital large amount of information transmission and multidimensional, can construct stereoscopic teaching environment, promote the teacher and the teacher, students and teachers, the multimodal interaction between students and students.

Multimedia teaching in the teaching of multimodal interaction between subject and object. Multimedia environment exist not only the multimodal interaction between the teaching subject, teaching also can produce multimodal interaction between subject and object, such as students and the interaction of the network environment and network (including the individual, community and network) [5]. The interaction between students and problem situation (including individual and situational, group and situation), the teachers and the interaction of the network environment, etc. This kind of interaction can communicate between them, to give evaluation and feedback, to jointly promote the development of the teaching process.

Between the multimedia teaching in the teaching object of multimodal interaction. In multimedia teaching, the teaching object between multimodal include: the size of the sound, sound, tone, the frequency of the sound, tone color, brightness, shape, size and font, space layout and so on, these along with the language of the media form the transfer of meaning in language not only have the effect of auxiliary, complement and strengthen, and even the whole meaning in language expression plays a very important role, sometimes is the key role, because it can cause the change of the whole meaning. Therefore, can be thought of each modal are symbolic resources, play a positive role to the construction of meaning. So involved in the multimedia teaching modal interaction and collaboration between internal media, such as books and PPT, the PPT by color, brightness, and highlight the font to highlight the key information, while books provide specific information, make up for the PPT to provide specific information in the framework. In English teaching, the sense of touch is the main mode, main communication process; Visual and auditory main reinforcement and complementary role [6]. While the use of multimodal can attract students' attention, and can stimulate students' enthusiasm and interest. Therefore, the media should be coordinated between, the relationship between joint and cross. In coordination, the different modal expression together the overall significance of the communicator, the lack of any person will not be complete. And in the same mode, different types of media can form joint relationship, to common sense, for example the multimodal discourse in the form of the video, and animation matching with the voice of the explanation reflects the sense of hearing. In multimodal interaction, at the same time to participate in a variety of media communication, through a variety of modal stimulate the senses at the same time, improve the effectiveness of.

Multimodal interaction. Is not only a cognitive behavior, and social and cooperative, the build process is a complex knowledge, require the existence of the real scene, need to students and teachers, interaction between students and students and cooperation [6]. In the network of multimodal interaction in English classroom, interactive two-way interaction is a comprehensive, multi-level integrated system, including teachers and students are the main body, is a mutual interaction of equality of personality sense, that can give full play to the teachers and students both sides in the process of subjective initiative, form mutual dialogue and discussion, a teaching mode that communicate with each other and promote each other. The interaction between teachers and students to promote the interaction between teachers and content, the interaction between the teacher and content and can promote the interaction between students and the content, eventually led to the quality of interaction between teachers and students to further improve [6]. Also, students and content of interaction number increase, will also contribute to the number of teachers interact with the content increase. Other conditions can be so on. There is interaction between a variety of interactive complementary action (i. e. , the perfection of a kind of interaction will also improve other interaction), eventually form in computer network system and resources as the center, dominated by teachers and centered on students, fully embodies the multi-dimensional interaction between 
student's subject status and student three-dimensional interactive learning system, to mobilize students' learning initiative and self-consciousness of different levels. This kind of teaching model of multimodal interaction not only cultivate the students' information literacy, also improve the teachers' ability to use modern education technology to teaching.

\section{Summary}

English teaching use only a single modal symbol is unable to attract students' attention and interest, and multimodal teaching mode to promote students' English learning from passive to active, promote the common progress of teaching and learning, teachers and students of common development. The use of multimedia auxiliary teaching attempt and explore in the process, for any things used to have a degree. Multimedia technology teaching AIDS, only if blindly rely on, the use of multimedia, or use the multimedia teaching, the teacher loses the role of guide and mentor. In the teaching process, it is necessary to exert the principal role of students. Also avoid courseware on a large number of voice, image information, due to invalid information, it will distract students' attention, influence the realization of teaching goal, made English class lesson of courseware.

\section{References}

[1] D.L. Zhang, Comprehensive theoretical framework to explore multimodal discourse analysis, Journal of foreign languages in China, 2009, vol.1, pp.24-30.

[2] D.L. Zhang, Multimodal discourse theory and the application of media technology in foreign language teaching, Foreign language teaching, 2009, vol.4, pp.15-20.

[3] R.R. Xie, The classroom teaching on multimodal discourse analysis, Journal of education theory and practice, 2011, vol.13, pp.46-49.

[4] L.T. Lin, Multimodal discourse analysis theory in college English teaching the application, Journal of education research, 2012, vol.2, pp.12-16.

[5] J.W. Yuan, Stent role in foreign language classroom interaction, Journal of Changchun normal university (Humanities and Social science edition), 2007, vol.5, pp.35-41.

[6] Y.Sh. Zhu, Multimodal discourse analysis on the theoretical basis and research methods, Journal of foreign languages, 2007, vol.7, pp.50-54. 